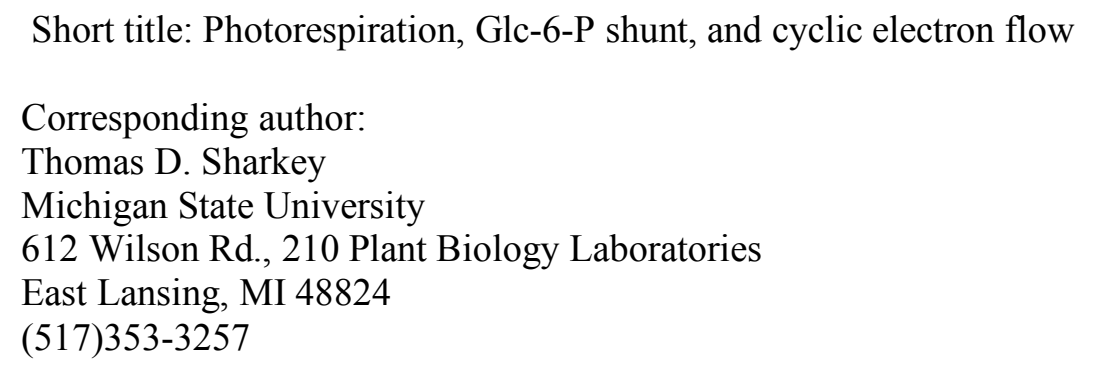

\title{
Loss of Peroxisomal Hydroxypyruvate Reductase Inhibits Triose Phosphate Isomerase but Stimulates Cyclic Photosynthetic Electron Flow and the Glc-6P-Phosphate Shunt ${ }^{1}$
}

Jiying Li ${ }^{\mathrm{a}, \$}$ Sarathi M. Weraduwage, ${ }^{\mathrm{a}}$ Alyssa L. Preiser, ${ }^{\mathrm{a}}$ Sean E. Weise, ${ }^{\mathrm{a}, \mathrm{b}}$ Deserah D. Strand ${ }^{\mathrm{a},+}$, John E. Froehlich, ${ }^{\text {a,b }}$ David M. Kramer, ${ }^{\mathrm{a}, \mathrm{b}}$ Jianping Hu, ${ }^{\mathrm{a}, \mathrm{c}}$ Thomas D. Sharkey ${ }^{\mathrm{a}, \mathrm{b}, \mathrm{d}, 2}$

${ }^{a}$ Michigan State University-Department of Energy Plant Research Laboratory, Michigan State University, East Lansing, MI 48824

${ }^{b}$ Department of Biochemistry and Molecular Biology, Michigan State University, East Lansing, MI 48824. ${ }^{\mathrm{c}}$ Department of Plant Biology, Michigan State University, East Lansing, MI 48824

${ }^{\mathrm{d} P}$ Plant Resilience Institute, Michigan State University, East Lansing, MI 48824

Once Sentence Summary: Triose phosphate isomerase is inhibited in plants lacking hydroxypyruvate reductase 1 and this is overcome by exporting triose phosphate to the cytosol and importing Glc-6P, which stimulates a Glc-6P-phosphate shunt and cyclic electron flow.

J.L., D.M. Kramer and J.H. conceived the original screening and research plans; J.L., S.W., A.L.P, D.D.S., and J.F. performed most of the experiments; S.E.W. provided technical assistance to J.L.; J.L., S.E.W. and T.D.S. designed the experiments and analyzed the data; T.D.S. wrote the article with contributions of all the authors.

${ }^{\$}$ Present address: Department of Computer Science, University of California, Davis CA 95616. ${ }^{+}$Present address: Max-Planck-Institut für Molekulare Pflanzenphysiologie, Am Mühlenberg 1, Potsdam-Golm, Germany

${ }^{1}$ Research funded by U.S. Department of Energy Grant DE-FG02-91ER2002. Partial salary support for TDS comes from Michigan AgBioResearch. 


\section{ABSTRACT}

The oxygenation of ribulose 1,5-bisphosphate by Rubisco is the first step in photorespiration and reduces the efficiency of photosynthesis in $\mathrm{C}_{3}$ plants. Our recent data indicates that mutants in photorespiration have increased rates of photosynthetic cyclic electron flow around photosystem I. We investigated mutant lines lacking peroxisomal hydroxypyruvate reductase to determine if there are connections between 2-PG accumulation and cyclic electron flow. We found that 2-PG is a competitive inhibitor of triose phosphate isomerase (TPI), an enzyme in the Calvin-Benson cycle that converts glyceraldehyde 3-phosphate to dihydroxyacetone phosphate. This block in metabolism could be overcome if glyceraldehyde 3-phosphate is exported to the cytosol where the cytosolic triose phosphate isomerase could convert it to dihydroxyacetone phosphate. We found evidence that carbon is reimported as Glc-6P-phosphate forming a cytosolic bypass around the block of stromal TPI. However, this also stimulates a Glc-6P-phosphate shunt, which consumes ATP, which can be compensated by higher rates of cyclic electron flow.

\section{INTRODUCTION}

Photorespiration occurs when ribulose bisphosphate $(\mathrm{RuBP})$ is oxygenated instead of carboxylated by Rubisco (Bowes et al., 1971). Oxygenation is an unavoidable consequence of the reaction mechanism of Rubisco, and once oxygenation occurs the remainder of photorespiratory metabolism reduces the cost of oxygenation (Andrews and Lorimer, 1978). Photorespiration reduces photosynthesis by three mechanisms: (1) reduction of Rubisco efficiency (increase in apparent $K_{\mathrm{m}}$ for $\mathrm{CO}_{2}$ ); (2) diversion of ATP and NADPH from carboxylation products to the photorespiratory pathway; and (3) release of $\mathrm{CO}_{2}$ in the photorespiratory pathway. These three effects significantly reduce the photosynthetic rate in $\mathrm{C}_{3}$ plants (Sharkey, 1988) and likely provided evolutionary pressure that resulted in C4 metabolism (Sage et al., 2012). Photorespiration is also a source of $\mathrm{H}_{2} \mathrm{O}_{2}$ and can affect the redox status of plant cells (Foyer et al., 2009).

Although photorespiration will decline as atmospheric $\mathrm{CO}_{2}$ increases, it will remain a significant issue for $\mathrm{C}_{3}$ photosynthesis for a long time (Walker et al., 2016b). Using a spreadsheet available here (Sharkey, 2016) it can be calculated that the ratio of oxygenation to carboxylation at $25^{\circ} \mathrm{C}$ for a plant with Rubisco with kinetics found in Arabidopsis thaliana would be 0.53 at preindustrial $\mathrm{CO}_{2}$ of $290 \mathrm{ppm}, 0.39$ at today's level of $\sim 400 \mathrm{ppm}$, and 0.26 when the $\mathrm{CO}_{2}$ concentration is $600 \mathrm{ppm}$ (assuming that $\mathrm{CO}_{2}$ at Rubisco is $50 \%$ of that in air because of diffusion resistances at the stomata and in the mesophyll). Engineering alternative photorespiration pathways to ameliorate the negative effects of photorespiration on plant growth is currently under investigation (Kebeish et al., 2007; Peterhänsel et al., 2013; Dalal et al., 2015; Xin et al., 2015; Betti et al., 2016; Engqvist and Maurino, 2017).

Photorespiratory metabolism converts two molecules of the first product of oxygenation, 2phosphglycolate (2-PG), to one molecule of 3-phosphoglycerate (PGA) and one molecule of $\mathrm{CO}_{2}$. Ordinarily, photorespiration proceeds at the rate needed to metabolize all of the 2-PG produced by oxygenation. Douce and Heldt (2000) conclude that "the only control step in the photorespiratory cycle is the level of competition between $\mathrm{O}_{2}$ and $\mathrm{CO}_{2}$ for binding to Rubisco." A number of the enzymes and transporters needed for photorespiration were discovered because plants lacking genes for these proteins can grow in a high $\mathrm{CO}_{2}$ atmosphere but not in air (Somerville and Ogren, 1979; Somerville, 1984).

It is assumed that the intermediates of photorespiration reduce the capacity of the Calvin-Benson cycle (Betti et al., 2016). Anderson (1971) showed that a very low concentration of 2-PG significantly inhibited triose phosphate isomerase (TPI), an enzyme that converts glyceraldehyde 3-phosphate (GAP) to dihydroxyacetone phosphate (DHAP). Somerville and Ogren (1979) showed that plants lacking 
phosphoglycolate phosphatase accumulate 2-PG and, based on Anderson's work, proposed this would cause more triose phosphate to be exported from chloroplasts, favoring sucrose synthesis. By altering the amount of phosphoglycolate phosphatase, Flügel et al. (2017) confirmed the inhibition of TPI by 2-PG and found less starch in plants with high 2-PG but did not find increased sucrose. Xu et al. (2009) reported that plants lacking some activity of glycolate oxidase had reduced activation of Rubisco and less mRNA for Rubisco activase than controls when grown in air but more Rubisco activase mRNA when grown in elevated $\mathrm{CO}_{2}(0.5 \%)$. Walker et al. (2016a) found reduced Rubisco activation ratio in plants lacking the glycerate/glycolate transporter PLGG1. Flügge et al. (1980) showed that glyoxylate could cause acidification of the stroma and so inhibit $\mathrm{pH}$-sensitive enzymes in the Calvin-Benson cycle, but this effect was not specific to glyoxylate, other organic acids had the same effect. Kelly and Latzko (1976) reported that 2-PG (but not glycolate) inhibited phosphofructokinase, which they postulated could interfere with starch breakdown at night. However, there should be no 2-PG present when starch is breaking down and current thinking about starch breakdown does not include a role for phosphofructokinase (Stitt and Zeeman, 2012).

Most of the enzymes and transporters of photorespiratory metabolism are essential; plants that lack them are very stunted or die when grown in air. However, plants missing NADH-dependent hydroxypyruvate reductase in the peroxisome ( $h p r 1)$ show only modest effects (Timm et al., 2008; Cousins et al., 2011; Timm et al., 2012). It is known that hydroxypyruvate can leave the peroxisome and be acted on by a cytosolic HPR (encoded by HPR2) that prefers NADPH (Kleczkowski et al., 1988; Timm et al., 2008). In addition, there is a multifunctional glyoxylate/hydroxypyruvate reductase in the chloroplast that prefers NADPH (Tolbert et al., 1970) that has now been identified as HPR3 (Timm et al., 2011). Loss of HPR1 and 2, or all three, results in severe growth defects in air but not high $\mathrm{CO}_{2}$ (Timm et al., 2008; Cousins et al., 2011; Timm et al., 2011). In addition, it has been hypothesized that some carbon leaves the photorespiratory pathway as glycine or serine (Harley and Sharkey, 1991; Busch et al., 2018). Despite these alternatives, plants lacking HPR 1 are typically stunted indicating that reduction of hydroxypyruvate is necessary for optimal photosynthesis.

In a recent survey of mutants of peroxisomal proteins using the Dynamic Environment Phenotype Imager (Cruz et al., 2016), many of the mutants exhibited significant phenotypes under high and fluctuating light but little phenotype under the low, constant light normally used to grow Arabidopsis thaliana. For instance, hpr 1-1, plgg1, and cat2-1 showed a significant increase in cyclic electron flow around photosystem I (CEF).

In this study, we investigated potential mechanisms by which a block in photorespiration could stimulate CEF. HPR 1 was chosen as the focus of the study because $h p r 1$ plants grow reasonably well but still show a strong stimulation of CEF. Also, HPR1 was identified as playing a role in drought tolerance ( $\mathrm{Li}$ and $\mathrm{Hu}$, 2015). We measured amounts of accumulated 2-PG. We then looked at how 2-PG might affect the CalvinBenson cycle and how those effects might lead to CEF. We postulate that the block of stromal TPI can be bypassed by export of GAP followed by reimport of carbon into the chloroplast. However, this cytosolic bypass of the gluconeogenic reactions of the Calvin-Benson cycle leads to a stimulation of a Glc-6-P shunt (Sharkey and Weise, 2016) that consumes ATP, leading to CEF.

\section{RESULTS}

\section{Growth, Chlorophyll, Carotenoid Contents and Rubisco Activity of hpr1 Plants}

Both hpr 1-1 and hpr 1-2 plants showed a stunted phenotype when grown in air in these experiemnts (Fig. 
the same in all three lines (Fig. 2 A). The amount of Rubisco activase protein was less in the two mutant lines than WT (Fig. 2 B). The activation state of Rubisco was modestly lower in low light $\left(125 \mu \mathrm{mol} \mathrm{m}^{-2}\right.$ $\mathrm{s}^{-1}$ ) in hprl-1 but not hprl-2 (Fig. $2 \mathrm{C}$ ). After incubation in high light $\left(1000 \mu \mathrm{mol}\right.$ photons $\left.\mathrm{m}^{-2} \mathrm{~s}^{-1}\right)$ the activation state of Rubisco was higher in all three lines but did not differ among lines (Fig. 2 D).

\section{2-PG Content of Leaves is High in hpr1-1 and hpr1-2}

The content of 2-PG was measured by LC/MS-MS. The results are expressed as peak area for 2-PG relative to the peak area of the internal standard, $\left({ }^{13} \mathrm{C}_{6}\right.$ fructose 1,6-bisphosphate). The 2-PG content was significantly increased in the hpr 1-1 plants (Fig. 3). In hpr l-2 plants the level appeared higher (Fig. 3) but the difference did not reach statistical significance.

\section{Effect of 2-PG on TPI Activity}

The effect of 2-PG on TPI was tested. 2-PG was a strong inhibitor of TPI and was competitive with GAP (Fig. 4). The $K_{i}$ was $24.2 \mu \mathrm{M}$, between the two values reported previously (Anderson, 1971; Flügel et al., 2017). The relative effect this would have on TPI depends on the concentrations of GAP and 2-PG. To test whether the 2-PG was limiting the activity of TPI in vivo we measured the concentrations of the triose phosphates. The concentration of DHAP was the same in Col-0 and hprl-1 but the concentration of GAP was about two-fold higher in hprl-1 than in Col-0 (Fig. 5) (note that GAP data have been multiplied by 10). Because GAP is the molecule first produced in the stroma, an inhibition of TPI would be expected to cause a buildup of GAP. At equilibrium, the DHAP/GAP ratio is expected to be 21.5 (Sharkey and Weise, 2012). In Col-0 this ratio was 11.3. and in hprl-1 the ratio was 6.1 consistent with a block in TPI activity affecting the Calvin-Benson cycle but also consistent with lack of equilibrium in Col-0.

\section{Expression of the GPT2 Gene}

It has been hypothesized that plants that lack chloroplastic fructose bisphosphatase might create a bypass by exporting more carbon to the cytosol and then reimporting carbon, possibly as Glc-6-P though the GPT2 transporter (Kossmann et al., 1994; Sharkey and Weise, 2016). We tested whether the hpr 1-1 plants with inhibited stromal TPI could make use of cytosolic TPI (since there would be no 2-PG in the cytosol) by reimporting carbon as Glc-6-P through the GPT2 transporter. When plants were grown and sampled in low light $\left(125 \mu \mathrm{mol}\right.$ photons $\left.\mathrm{m}^{-2} \mathrm{~s}^{-1}\right)$ there was no difference in the transcript levels for GPT2 (Fig. 6 A). However, after exposing plants to $1000 \mu \mathrm{mol}$ photons $\mathrm{m}^{-2} \mathrm{~s}^{-1}$ for 6 hours, transcripts for GPT2 were up four-fold in Col-0 plants and ten-fold in hpr 1-1 plants (Fig. 6 B) (note the ten-fold difference in the scale). Plants lacking the glycerate/glyoxylate transporter (plggl) also had increased GPT2 expression. These plants have increased glycolate (Pick et al., 2013) and presumably 2-PG, as found in the hpr 1-1 mutant. However, plants lacking either of two other photorespiratory genes, cat2, or gox 1, did not exhibit increased levels of GPT2 mRNA beyond that seen in Col-0 (Fig. 6).

\section{DISCUSSION}

Inhibition of photorespiratory metabolism, other than Rubisco oxygenase activity, results in reduced plant health. A major cause is reduced activity of TPI because of competitive inhibition by 2-PG. Flügel et al. (2017) showed that this led to reduced fructose 1,6-bisphosphate and also sedoheptulose 1,7bisphosphate, two metabolites that require DHAP for synthesis. Although 2-PG is near the beginning of the pathway and HPR is near the end, loss of HPR activity caused a buildup of 2-PG. Plants lacking HPR1 also accumulate glycolate (Timm et al., 2012). In this study, we found that the ratio of DHAP to GAP was reduced by nearly $50 \%$ in $h p r l-1$ compared to Col- 0 . The triose phosphates were not in equilibrium even in the wild type Col-0. A lack of equilibrium at this step was hypothesized in the original publication of the Calvin-Benson cycle (Bassham et al., 1954). They suggested that a lack of 
equilibrium in this step could explain their observed lower-than-predicted labeling of carbon 4 in sedoheptulose bisphosphate during very short labeling. The lack of equilibrium at TPI can also explain the "Gibbs effect" in which C4 of hexoses is more heavily labeled than C3 (Kandler and Gibbs, 1956; Gibbs and Kandler, 1957). The larger amount of DHAP relative to GAP can also contribute to the disequilibrium of label in carbons 3 and 4 (Ebenhöh and Spelberg, 2018) but the TPI disequilibrium significantly exacerbates the disequilibrium. Therefore, despite its reputation for efficiency, TPI activity is not in excess during photosynthesis and the inhibition of TPI by 2-PG can have a significant effect on metabolism. To overcome the inhibition of TPI, GAP can be exported to the cytosol where, in the absence of 2-PG, TPI can function.

We also tested whether Rubisco activase could play a role in the inhibition of photosynthesis when photorespiratory metabolism is blocked. The growth conditions used in our study resulted in smaller plants with less chlorophyll and carotenoid per leaf area (Fig. 1) and hence the block in photorespiration was affecting plant growth. However, the total activity of Rubisco was the same in Col-0 and two mutant lines (Fig. 2 A). The amount of Rubisco activase protein was less in the mutant lines (Fig. 2 B) consistent with the observation of reduced Rubisco activase message seen by Xu et al. (2009) but Rubisco activation state was lower in only one line and only at low light (Fig. 2 C). Although this could affect how well plants could cope with a stochastic light environment (Taylor and Long, 2017), we conclude from these results that effects on Rubisco activation may be secondary to the main effects of TPI inhibition and the rest of the discussion will focus on the possible consequences of TPI inhibition.

Export of carbon for processing in the cytosol, as proposed here for TPI inhibition, has been proposed for other mutants. Sharkey and Weise (2017) hypothesized that a block in stromal FBPase can be bypassed by export of carbon to the cytosol. Carbon is then reimported into the chloroplast beyond the FBPase step in the Calvin-Benson cycle (Kossmann et al., 1994; Sharkey and Weise, 2016). A mutant lacking fructose 1,6 bisphosphate aldolase also exhibits high rates of CEF (Gotoh et al., 2010). In this mutant carbon could be exported as triose phosphates and then reimported as Glc-6-P to bypass the FBP aldolase step. We hypothesize that in these three cases (and perhaps others) carbon can be exported to the cytosol to bypass missing or limited enzymes of the Calvin-Benson cycle and then reimported into the chloroplast.

However, the gradient for triose phosphate reimport is unfavorable. The phosphate concentration is much higher in the cytosol than in the stroma (Sharkey and Vanderveer, 1989), which aids in triose phosphate export but would slow triose phosphate reimport. On the other hand, the gradient for Glc-6-P is highly favorable for import into the chloroplast (Gerhardt et al., 1987; Sharkey and Vassey, 1989; Szecowka et al., 2013) and could overcome the unfavorable phosphate gradient. Stimulation of GPT2 expression would allow carbon to be reimported into the chloroplast as Glc-6-P. Transcripts for GPT2 were elevated in hprl-1 and plggl (Fig. 7) but not in cat2 and goxl. We saw that 2-PG was elevated in hprl-1. Pick et al. (2013) saw that glycolate is elevated in $\operatorname{plgg} 1$ and it is very likely that 2-PG is also elevated in this mutant. Since cat 2 and gox 1 are important for redox control but not carbon metabolism, and because there is redundancy of both catalase and GOX genes, perhaps cat2 and gox 1 do not have elevated 2-PG [cat2 does not have elevated glycolate (Kerchev et al., 2016)] and so do not result in a signal to increase the expression of GPT2.

Figure 7 shows a model for the metabolic changes in hpr 1-1. In Col-0 (top) carbon is exported from the chloroplast for sucrose synthesis but once cytosolic FBPase acts, the carbon can no longer return to the chloroplast because there is only minimal capacity for G1P import (Fettke et al., 2011) and normally no capacity for Glc-6-P import. However, in the hprl-1 mutant (bottom) 2-PG inhibits TPI. GAP can be exported and DHAP is made in the cytosol because 2-PG is restricted to the chloroplast. However, phosphate is in high concentration in the cytosol and much lower in the chloroplast (Sharkey and Vanderveer, 1989) making it difficult for DHAP to be imported into the stroma at sufficiently high rates. Moreover, the high concentrations of triose phosphates in the cytosol could lead to FBP synthesis and 
dephosphorylation. Once FBP is converted to Fru-6-P by cytosolic FBPase, carbon could only reenter the stroma as hexose phosphate. Induction of GPT2 would allow carbon to be reimported as Glc-6-P. Once Glc-6-P is reimported into the chloroplast it can rejoin the Calvin-Benson cycle when it is converted to Fru-6-P by PGI. This would result in a cytosolic bypass around the inhibited TPI.

However, stromal PGI is kinetically limited (Backhausen et al., 1997). The Fru-6-P to Glc-6-P ratios are normally 1:1 in the stroma, well below the predicted ratio and well below the ratio found in the cytosol (Gerhardt et al., 1987; Sharkey and Vassey, 1989; Szecowka et al., 2013). The $K_{m}$ of PGI for Glc-6-P is much higher than the $K_{m}$ for Fru-6-P (Schnarrenberger and Oeser, 1974)( Table 1 of this paper shows the opposite but this is in error as can be deduced from the text and abstract and as confirmed by our own unpublished results). GPT2 would allow a very high concentration of Glc-6-P in the stroma. Because stromal Glc-6-P dehydrogenase (G6PDH) has a high $K_{m}$ when it is reduced (Scheibe et al., 1989; Hauschild, 2003), a high concentration of Glc-6-P could overcome the light-induced changes in G6PDH that normally restrict its activity during the day. This would stimulate the oxidative branch of the pentose phosphate pathway making a Glc-6-P shunt around the Calvin-Benson cycle (Sharkey and Weise, 2016).

The Glc-6-P shunt results in a release of $\mathrm{CO}_{2}$. This release would appear similar to the release of $\mathrm{CO}_{2}$ during photorespiration. Cousins et al. (2011) reported that hprl-1 mutants exhibited higher than expected $\mathrm{CO}_{2}$ release that was oxygen dependent. Plants lacking peroxisomal malate dehydrogenase, needed for HPR1 function, also released more than expected amounts of $\mathrm{CO}_{2}$ (Cousins et al., 2008). We speculate that the excess $\mathrm{CO}_{2}$ release seen in these studies results from the $\mathrm{CO}_{2}$ released during the Glc-6-P shunt.

The Glc-6-P shunt consumes 3 ATP but is balanced for NADPH and carbon. Stimulation of this shunt would require significantly more ATP and so CEF could be favored. This provides a mechanism for connecting carbon metabolism changes with electron transport changes. If true, then other photorespiratory mutants that had been shown to contain elevated 2-PG levels should also show elevated CEF. Other mutants that reduce stromal FBP should also show elevated CEF because carbon would avoid these blockages through the cytosolic bypass leading to increased rates of the Glc-6-P shunt. Gotoh et al. (2010) reported a strong stimulation of CEF in a mutant lacking stromal Fru-1,6-bisP aldolase, and plants lacking stromal FBPase also have high rates of cyclic electron flow (Livingston et al., 2010), which is consistent with a cytosolic bypass leading to a Glc-6-P shunt (Fig. 7). There remain unanswered questions, especially how the use of ATP in the Glc-6-P shunt results in a signal to increase CEF and the role of $\mathrm{H}_{2} \mathrm{O}_{2}$ in $\mathrm{CEF}$ (Strand et al., 2015) and other metabolism.

Finally, hydoxypyruvate reductase is only required if a significant amount of carbon that originates as 2PG completes the photorespiratory pathway and becomes glycerate or $\mathrm{CO}_{2}$. Some hydroxypyruvate can be reduced by other HPRs (Tolbert et al., 1970; Kleczkowski et al., 1988; Timm et al., 2008; Cousins et al., 2011; Timm et al., 2011). In addition, there are indications that some carbon can leave the photorespiratory cycle as glycine or serine, but that would be limited by how fast nitrogen is made available (Harley and Sharkey, 1991; Busch et al., 2018). While the effect of the loss of HPR1 alone is not as great as the loss of other photorespiratory enzymes, for example 2-PG phosphatase (Somerville and Ogren, 1979), it nevertheless can impair plant growth indicating that a significant fraction of carbon that begins the photorespiratory cycle as a result of oxygenation is reduced by HPR1 and completes the cycle. Nevertheless, because of the alternative paths for hydroxypyruvate reduction, $h p r l$ plants are useful for study of the effects of an impairment, but not loss, of photorespiration.

\section{Plant Material}


Col-0, hpr 1-1, and hpr1-2 were used. The hpr1 plants (Salk 067724 and 143584) were the same as reported on by (Timm et al., 2008), who showed that no HPR protein was detectable. Plants were grown in Redi-earth potting medium under a 16-h photoperiod. Growth chamber conditions were set to: 120 $\mu \mathrm{mol} \mathrm{m} \mathrm{s}^{-1}$ light intensity, day- and night-time temperatures of $22-23^{\circ} \mathrm{C}$ and $20^{\circ} \mathrm{C}$, and $60 \%$ relative humidity. For high light treatment, plants were exposed to a light intensity of $1000 \mu \mathrm{mol} \mathrm{m}^{-2} \mathrm{~s}^{-1}$ for $6 \mathrm{hr}$ unless otherwise noted.

\section{Measurement of Chlorophyll and Carotenoid}

For chlorophyll measurement, two leaf discs were harvested from 4-week old rosettes, and chlorophyll was extracted in $2 \mathrm{~mL}$ of $96 \%$ ethanol using a protocol modified from Lichtenthaler and Wellburn (1983). The homogenate was maintained under dark conditions to prevent chlorophyll degradation. Absorbance of each tube at $470 \mathrm{~nm}, 649 \mathrm{~nm}$ and $665 \mathrm{~nm}$ were measured with a spectrophotometer. The chlorophyll a, $\mathrm{b}$, and carotenoid content was calculated as follows: chlorophyll a $(\mu \mathrm{g} / \mathrm{mL})=13.95 A_{665}-6.88 A_{649}$; chlorophyll $\mathrm{b}=24.96 A_{649}-7.32 A_{665}$; carotenoids $=\left(1000 A_{470}-2.05 \mathrm{C}_{\mathrm{a}}-114.8 \mathrm{C}_{\mathrm{b}}\right) / 245($ Lichtenthaler and Wellburn 1983). Pigment concentration was expressed in $\mathrm{g} \mathrm{m}^{-2}$ of leaf tissue.

\section{Measurement of Rubisco Activity and Protein Levels of Rubisco Activase}

Leaves from 4-week old rosettes were harvested quickly into liquid $\mathrm{N}_{2}$, and stored in a $-80{ }^{\circ} \mathrm{C}$ freezer. Rubisco activity was measured using a protocol modified from Sharkey et al. (1986) and Sharkey et al. (2001). Leaf tissue was ground with the aid of a Retch mill (Retsch, http://www.retsch.com/) and protein was extracted into $2 \mathrm{~mL}$ of extraction buffer (50 mM EPPS pH 8.0,30 mM NaCl, $10 \mathrm{mM}$ mannitol, 5 $\mathrm{mM} \mathrm{MgCl}_{2}, 2$ mM EDTA, $5 \mathrm{mM}$ DTT, $0.5 \%$ Triton $\mathrm{x}-100,1 \%$ PVPP, $0.5 \%$ casein, $1 \%$ protease inhibitor cocktail-P9599 Sigma). To obtain initial activity, $20 \mu \mathrm{L}$ of extract was added to $80 \mu \mathrm{L}$ of assay buffer (50 $\mathrm{mM}$ EPPS pH 8.0, $5 \mathrm{mM} \mathrm{MgCl}_{2}, 0.2 \mathrm{mM}$ EDTA, $0.5 \mathrm{mM} \mathrm{RuBP}, 15 \mathrm{mM} \mathrm{H}^{14} \mathrm{CO}_{3}{ }^{-}$) in a 7-mL scintillation vial. After a $1 \mathrm{~min}$ incubation, $100 \mu \mathrm{L}$ of $1 \mathrm{M}$ formic acid was added to stop the reaction and release unreacted bicarbonate. The mixture was then dried and the amount of radioactivity that was fixed was determined with the aid of a liquid scintillation analyzer (Tri-Carb2800TR, PerkinElmer). In order to determine total activity, $200 \mu \mathrm{L}$ of the initial extract was added to $20 \mu \mathrm{L}$ of activating solution (to give final concentrations of $20 \mathrm{mM} \mathrm{MgCl}_{2}, 15 \mathrm{mM} \mathrm{H}^{14} \mathrm{CO}_{3}^{-}, 61 \mu \mathrm{M}$ 6-phospho-gluconate) and incubated for $10 \mathrm{~min}$. Total Rubisco activity of the activated sample was assayed as explained above. Each day, radioactivity in $10 \mu \mathrm{L}$ of the assay buffer was counted to determine specific activity. Based on $1 \mathrm{mCi}=$ $2.22 \times 10^{9}$ distintegrations $\mathrm{min}^{-1}$, initial and total Rubisco activity was calculated and expressed as $\mu \mathrm{mol}$ $\mathrm{m}^{-2} \mathrm{~s}^{-1}$. The rates were divided by 0.943 to account for the discrimination against ${ }^{14} \mathrm{C}$ by (Roeske and O'Leary, 1984).

To determine Rubisco activase protein content, total protein was extracted using a PlantTotal Protein Extraction Kit (PE0230, Sigma-Aldrich, MO, USA) from 4-week old rosette leaves. Total protein concentration in the extracts was measured by carrying out a modified Lowry Assay, and denaturing polyacrylamide gel electrophoresis was performed to determine the purity and quality of the extracted protein. For quantification, equal amounts of total protein from each sample were loaded onto an automated capillary-based size western blotting system (ProteinSimple Wes System, San Jose CA, USA). Rubisco activase in each protein sample was detected using antibodies raised against rubisco activase (rabbit, AS10700; Agrisera, Sweden). Data analysis was carried out using Compass Software (ProteinSimple, San Jose CA).

\section{Measurement of 2-Phosphoglycolate}

Eight-week-old plants were treated with 125 or $1000 \mu \mathrm{mol} \mathrm{m}^{-2} \mathrm{~s}^{-1}$ light for six hours. After treatment, leaf tissue was harvested and immediately frozen in liquid nitrogen before being stored at $-80{ }^{\circ} \mathrm{C}$. Samples 
were finely ground using a chilled mortar and pestle. Metabolites were extracted with 3:71:26 ethanol/formic acid/water (v/v). After centrifuging the supernatant was freeze dried, re-suspended in acetonitrile, and filtered through Mini-Uniprep Syringless Filter Devices, $0.2 \mu \mathrm{m}$ (GE Healthcare).

LC/MS-MS was carried out on an Aquity UPLC Performance LC (Waters) and Quattro Premier XE (Micromass) in electrospray negative ion mode. The column used was an Acquity UPLC BEH Amide 1.7 $\mu \mathrm{m}, 2.1 \times 100 \mathrm{~mm}$ (Waters). Mass Lynx (v. 4.1, Waters) was used for data acquisition and analysis. Acquity Binary Solvent Manager (v. 1.40.1248) and Acquity Sample Manager (v. 1.40.2532) was used as the binary solvent manager. Capillary voltage was $2.75 \mathrm{kV}$, source temperature was $120{ }^{\circ} \mathrm{C}$ and desolvation temperature was $350^{\circ} \mathrm{C}$. Desolvation gas flow was set to $800 \mathrm{~L} / \mathrm{hr}$ and collision gas flow was $0.15 \mathrm{~mL} / \mathrm{min}$. Selected reaction monitoring was used to quantify levels of 2-PG. The parameters for monitoring 2-PG were trace of $153>97(\mathrm{~m} / \mathrm{z})$, cone voltage of $19 \mathrm{~V}$, and collision energy of $17 \mathrm{~V}$. Parameters for the internal standard $\left({ }^{13} \mathrm{C}_{6}\right.$ fructose 1,6-bisphosphate, Omicron) were trace of $345>97$ $(\mathrm{m} / \mathrm{z})$, cone voltage of $16 \mathrm{~V}$, and collision energy of $25 \mathrm{~V}$. A multi-step gradient was used with $10 \mathrm{mM}$ ammonium acetate in water (A) and acetonitrile (B). The flow rate was set to $0.3 \mathrm{~mL}$ min- 1 throughout the entire run. 0-1.0 $\min , 5 \% \mathrm{~A} ; 1.0-1.5 \mathrm{~min}, 5-100 \% \mathrm{~A} ; 1.5-3.0 \mathrm{~min}, 100 \% \mathrm{~A} ; 3.0-3.5 \mathrm{~min}, 100-5 \% \mathrm{~A}$; 3.5-4.0 $\mathrm{min}, 5 \% \mathrm{~A}$.

\section{Measurement of GAP, DHAP and TPI}

About $500 \mathrm{mg}$ fr wt of leaves were immediately freeze-clamped using aluminum blocks cooled on dry ice to stop metabolism fast enough to measure triose phosphates. Samples were weighed then fully pulverized using a Retsch Mill M300 (Retsch, http://www.retsch.com/). Cold 3.5\% perchloric acid (2 $\mu \mathrm{L}$ per $\mathrm{mg}$ tissue), was added and tubes were placed on ice for $5 \mathrm{~min}$ incubation. Extracts were centrifuged at maximum speed at $4^{\circ} \mathrm{C}$ for $10 \mathrm{~min}$. Approx. $500 \mu \mathrm{L}$ of supernatant was recovered. Neutralizing buffer $(2 \mathrm{M} \mathrm{KOH}, 150 \mathrm{mM}$ Hepes and $10 \mathrm{mM} \mathrm{KCl}$ ), in the ratio of $0.25 \mu \mathrm{L}$ per $\mu \mathrm{L}$ of recovered supernatant, was added to the supernatant to bring the $\mathrm{pH}$ to $\sim 7$. $\mathrm{pH}$ sticks were used to check the $\mathrm{pH}$; the volume of neutralizing buffer was adjusted accordingly, and the volume of neutralizing buffer was recorded. Samples were frozen and thawed to precipitate salts, and centrifuged at maximum speed for $2 \mathrm{~min}$. The supernatant was pipetted off for immediate GAP and DHAP assays, or frozen at $-80^{\circ} \mathrm{C}$ for future assays.

The amount of GAP and DHAP was measured using a dual wavelength filter photometer (Sigma ZFP22). Supernatant $(50 \mu \mathrm{L})$ was added to $800 \mu \mathrm{L}$ reaction buffer $(100 \mathrm{mM}$ Hepes buffer $\mathrm{pH}$ 7.6, $1 \mathrm{mM}$ DTT, 1 $\mathrm{mM} \mathrm{KH}_{2} \mathrm{AsO}_{4}, 50 \mathrm{mM} \mathrm{NAD}$ and $50 \mathrm{mM}$ ADP) in a cuvette, which was inserted into the cuvette holder in the spectrophotometer. Glyceraldehyde 3-phosphate dehydrogenase (5 U) (Sigma G-5537) was added to the cuvette and immediately mixed using a clean plastic stick. The difference of absorbance between the baseline and the maximum level was measured to estimate the level of GAP. Next, $5 \mathrm{U}$ of triose phosphate isomerase (Sigma T-6285) was added to convert DHAP to GAP. We used $\mathrm{A}_{334}-\mathrm{A}_{405}$ and an extinction coefficient of $6190 \mathrm{M}^{-1} \mathrm{~cm}^{-1}$.

Triose phosphate isomerase activity was measured by linking the production of DHAP from GAP to oxidation of NADH to NAD through glycerophosphate dehydrogenase as described in Anderson (1971). TPI from crude protein extracts of Arabidopsis leaves harvested from four-week-old rosettes was assayed in the presence of varying concentrations of $\operatorname{GAP}(0,0.2,0.4,0.7,2 \mathrm{mM})$ and $2-\mathrm{PG}(0,10,20,40,80$ $\mu \mathrm{M})$. The same dual wavelength filter photometer mentioned above was used to record the rate of change in absorbance at $334-405 \mathrm{~nm}$.

\section{Quantitative RT-PCR}


Arabidopsis total RNA was isolated using a Plant RNeasy kit according to the manufacturer's instructions (Qiagen, https://www.qiagen.com), and treated with DNase I. $500 \mathrm{ng}$ of each RNA sample was used for cDNA synthesis with random primers and iScript ${ }^{\mathrm{TM}}$ cDNA Synthesis Kit (Bio-rad, http://www.bio$\mathrm{rad} . \mathrm{com} /$ ). Quantitative real-time PCR was performed using a 7500 Fast Real-Time PCR System with Fast SYBR Green Master Mix (Applied Biosystems, http://www.appliedbiosystems.com). Gene expression was normalized to actin. Expression was determined in triplicate biological measurements.

\section{Statistics and Box Plots}

Differences between WT and treatments were tested by one way ANOVA followed by Tukey's test in Microcal Origin 8.0. Three levels of significance were test and indicated by,$+ \alpha=0.1 ; *, \alpha=0.05 ; * *, \alpha$ $=0.01$. Box plots are presented with the box encompassing the middle two quartiles, the mean shown as an open square inside the box, the median as a line inside the box, and the whiskers showing the standard deviation of the data.

Figure legends

Figure. 1. Rosette appearance of WT, hprl-1 and hprl-2 plants and measurement of pigments. (A) Plants after growing in Redi-earth for four weeks. Chlorophyll (B) and carotenoid contents(C) were measured as described in the Materials and Methods. Double asterisks indicate statistical significance at 0.01 tested by ANOVA followed by Tukey's test. $n=6$

418 Figure 2. Rubisco activity and activase protein. (A) Total Rubisco activity. (B) Amount of Rubisco Activase protein. (C-D) Rubisco activation state presented as the ratio between initial (I, measured as quickly as possible after extraction) and total ( $\mathrm{T}$, after incubation with 6-phosphogluconate, $\mathrm{HCO}_{3}{ }^{-}$and $\mathrm{Mg}^{2+}$ ) at 125 (C) or 1000 (D) $\mu \mathrm{mol}$ photons $\mathrm{m}^{-2} \mathrm{~s}^{-1}$. For A, C, and D $n=4-7$. For B, data were not different between the low and high light treatment and so was combined. The + sign and asterisks indicate statistical significance at 0.1 and 0.05 , respectively, tested by ANOVA followed by Tukey's test. $n=7-8$

Figure 3. 2-phosphoglycolate (2-PG) amounts in leaves of Col-0 and two hpr1 mutants. 2-PG was measured by HPLC-MS/MS using extracts of leaves harvested after $6 \mathrm{hr}$ in 125 or $1000 \mu \mathrm{mol}$ photons $\mathrm{m}^{-2}$ $\mathrm{s}^{-1}$. Because the data for both light intensities was indistinguishable they were combined to increase statistical power. Data are expressed as peak area of 2-PG divided by peak area of the internal standard $\left({ }^{13} \mathrm{C}_{6}\right.$ fructose 1,6-bisphosphate) relative to weight of plant material extracted. Asterisks indicate statistical significance at 0.05 tested by ANOVA followed by Tukey's test. $n=7-8$

430 Figure 4. Lineweaver-Burke plot of TPI activity. Triose phosphate isomerase in crude extracts of Arabidopsis leaves was assayed in the presence of a range of GAP and 2-PG concentrations. The numbers on each line is the concentration of 2-PG in $\mu \mathrm{M}$. The crossover of the lines at the $\mathrm{y}$ axis indicates that 2PG is a competitive inhibitor.

434 Figure 5. Amounts of DHAP and GAP. Leaves were treated with $1000 \mu \mathrm{mol}$ photons $\mathrm{m}^{-2} \mathrm{~s}^{-1}$ for six hours, then clamped with liquid-nitrogen-cooled copper blocks to stop metabolism in the light. Leaf samples were extracted with perchloric acid, neutralized, and then measured using sequential additions of GAP dehydrogenase and TPI while following NADH production photometrically. Unfilled boxes - 125 $\mu \mathrm{mol}$ photons $\mathrm{m}^{-2} \mathrm{~s}^{-1}$, grey boxes $-1000 \mu \mathrm{mol}$ photons $\mathrm{m}^{-2} \mathrm{~s}^{-1}$. Double asterisks indicate statistical significance at 0.01 tested by ANOVA followed by Tukey's test. $n=5$

440 Figure 6. Quantitative RT-PCR analysis of GPT2 transcripts in low and high light. Transcript amounts scale is 10-fold higher for the high light data, thus GPT2 transcript level was about four-fold higher after the high light treatment. Double asterisks indicate statistical significance at 0.01 tested by ANOVA followed by Tukey's test. $n=3$ 
Figure 7. Hypothesized carbon flow in Col-0 and hprl-1. The canonical path of carbon in the CalvinBenson cycle plus sucrose synthesis is shown for Col-0. In hpr 1-1 plants we hypothesize that 2-PG inhibits TPI, forcing export of GAP. Once acted on by cytosolic TPI, some DHAP will be reimported but the gradient in phosphate is not favorable for this flux. The triose phosphates in the cytosol will be converted eventually to Glc-6-P. Some unknown signal results in the expression of GPT2 allowing reimport of carbon as Glc-6-P. This allows some Calvin-Benson cycle activity but also stimulates the Glc-6-P shunt (shown in orange). The stimulated Glc-6-P shunt is balanced in terms of carbon and NADPH but consumes ATP, which generates an unknown signal that results in cyclic electron flow. PGA = phosphoglyceric acid, GAP = glyceraldehyde 3-phosphate, DHAP, dihydroxyacetone phosphate, FBP = fructose 1,6-bisphosphate, F6P = fructose 6-phosphate, $\mathrm{E} 4 \mathrm{P}=$ erythrose 4-phosphate, $\mathrm{S} 7 \mathrm{P}=$ sedoheptulose 7-phosphate, $\mathrm{R} 5 \mathrm{P}=$ ribose 5phosphate, $\mathrm{XuBP}=$ xylulose 5-phosphate, $\mathrm{Ru} 5 \mathrm{P}=$ ribulose 5-phosphate, $\mathrm{RuBP}=$ ribulose 1,5-bisphosphate, $\mathrm{SBP}=$ sedoheptulose 1,7-bisphosphate, $6 \mathrm{PG}=6$-phosphoglucanate.

Acknowledgements

We wish to thank Jim Klug and Cody Keilen (Growth Chamber Facility) of Michigan State University for their assistance. ABRC for seeds and Andreas Weber for plggl seeds.

\section{REFERENCES}

Anderson LE (1971) Chloroplast and cytoplasmic enzymes II. Pea leaf triose phosphate isomerases. Biochimica et Biophysica Acta (BBA) - Enzymology 235: 237-244

Andrews TJ, Lorimer GH (1978) Photorespiration — still unavoidable? FEBS Letters 90: 1-9

Backhausen JE, Jöstingmeyer P, Scheibe R (1997) Competitive inhibition of spinach leaf phosphoglucose isomerase isoenzymes by erythrose 4-phosphate. Plant Science 130: $121-131$

Bassham JA, Benson AA, Kay LD, Harris AZ, Wilson AT, Calvin M (1954) The path of carbon in photosynthesis. XXI. The cyclic regeneration of carbon dioxide acceptor. Journal of the American Chemical Society 76: 1760-1770

Betti M, Bauwe H, Busch FA, Fernie AR, Keech O, Levey M, Ort DR, Parry MAJ, Sage R, Timm S, Walker B, Weber APM (2016) Manipulating photorespiration to increase plant productivity: recent advances and perspectives for crop improvement. Journal of Experimental Botany 67: 2977-2988

Bowes G, Ogren WL, Hageman RH (1971) Phosphoglycolate production catalyzed by ribulose diphosphate carboxylase. Biochemistry and Biophysics Research Communications 45: 716-722

Busch FA, Sage RF, Farquhar GD (2018) Plants increase $\mathrm{CO}_{2}$ uptake by assimilating nitrogen via the photorespiratory pathway. Nature Plants 4: 46-54

Cousins A, Walker B, Pracharoenwattana I, Smith S, Badger M (2011) Peroxisomal hydroxypyruvate reductase is not essential for photorespiration in Arabidopsis but its absence causes an increase in the stoichiometry of photorespiratory $\mathrm{CO}_{2}$ release. Photosynthesis Research 108: 91-100 malate dehydrogenase is not essential for photorespiration in arabidopsis but its 
absence causes an increase in the stoichiometry of photorespiratory $\mathrm{CO}_{2}$ release.

Plant Physiology 148: 786

Cruz Jeffrey A, Savage LJ, Zegarac R, Hall Christopher C, Satoh-Cruz M, Davis Geoffry A, Kovac William K, Chen J, Kramer David M (2016) Dynamic environmental photosynthetic imaging reveals emergent phenotypes. Cell Systems 2: $365-377$

Dalal J, Lopez H, Vasani NB, Hu Z, Swift JE, Yalamanchili R, Dvora M, Lin X, Xie D, Qu R, Sederoff HW (2015) A photorespiratory bypass increases plant growth and seed yield in biofuel crop Camelina sativa. Biotechnology for biofuels 8: 175

Douce R, Heldt H-W (2000) Photorespiration. In L RC, S von Caemmerer, T Sharkey, eds, Photosynthesis: Physiology and Mechanisms. Kluwer, The Netherlands, pp 115-136

Ebenhöh 0, Spelberg S (2018) The importance of the photosynthetic Gibbs effect in the elucidation of the Calvin-Benson-Bassham cycle. Biochemical Society Transactions 46: 131

Engqvist MKM, Maurino VG (2017) Metabolic engineering of photorespiration. In AR Fernie, H Bauwe, APM Weber, eds, Photorespiration: Methods and Protocols. Springer New York, New York, NY, pp 137-155

Fettke J, Malinova I, Albrecht T, Hejazi M, Steup M (2011) Glucose-1-phosphate transport into protoplasts and chloroplasts from leaves of Arabidopsis. Plant Physiology 155: 1723-1734

Flügel F, Timm S, Arrivault S, Florian A, Stitt M, Fernie AR, Bauwe H (2017) The photorespiratory metabolite 2-phosphoglycolate regulates photosynthesis and starch accumulation in Arabidopsis. The Plant Cell

Flügge UI, Freisl, Heldt HW (1980) The Mechanism of the control of carbon fixation by the $\mathrm{pH}$ in the chloroplast stroma - Studies with acid mediated proton-transfer across the envelope. Planta 149: 48-51

Foyer CH, Bloom AJ, Queval G, Noctor G (2009) Photorespiratory metabolism: Genes, mutants, energetics, and redox signaling. Annual Review of Plant Biology 60: 455484

Gerhardt R, Stitt M, Heldt HW (1987) Subcellular metabolite levels in spinach leaves. Regulation of sucrose synthesis during diurnal alterations in photosynthetic partitioning. Plant Physiology 83: 399-407

Gibbs M, Kandler 0 (1957) Asymmetric distribution of $C^{14}$ in sugars formed during photosynthesis. Proceedings of the National Academy of Sciences 43: 446

Gotoh E, Matsumoto M, Ogawa Ki, Kobayashi Y, Tsuyama M (2010) A qualitative analysis of the regulation of cyclic electron flow around photosystem I from the post-illumination chlorophyll fluorescence transient in Arabidopsis: a new platform for the in vivo investigation of the chloroplast redox state. Photosynthesis Research 103: $111-123$

Harley PC, Sharkey TD (1991) An improved model of $\mathrm{C}_{3}$ photosynthesis at high $\mathrm{CO}_{2}$ : Reversed $\mathrm{O}_{2}$ sensitivity explained by lack of glycerate reentry into the chloroplast. Photosynthesis Research 27: 169-178

Hauschild R (2003) Differential regulation of glucose-6-phosphate dehydrogenase isoenzyme activities in potato. Plant Physiology 133: 47-62

Kandler 0, Gibbs M (1956) Asymmetric distribution of $\mathrm{C}^{14}$ in the glucose phosphates formed during photosynthesis. Plant Physiology 31: 411-412 
Kebeish R, Niessen M, Thiruveedhi K, Bari R, Hirsch HJ, Rosenkranz R, Stabler N, Schonfeld B, Kreuzaler F, Peterhänsel C (2007) Chloroplastic photorespiratory bypass increases photosynthesis and biomass production in Arabidopsis thaliana. Nat Biotechnol 25: 593-599

Kelly GJ, Latzko E (1976) Inhibition of spinach-leaf phosphofructokinase by 2phosphoglycollate. FEBS Letters 68: 55-58

Kerchev P, Waszczak C, Lewandowska A, Willems P, Shapiguzov A, Li Z, Alseekh S, Mühlenbock P, Hoeberichts FA, Huang J, Van Der Kelen K, Kangasjärvi J, Fernie AR, De Smet R, Van de Peer Y, Messens J, Van Breusegem F (2016) Lack of GLYCOLATE OXIDASE1, but not GLYCOLATE OXIDASE2, attenuates the photorespiratory phenotype of CATALASE2-deficient Arabidopsis. Plant Physiology 171: 1704

Kleczkowski LA, Givan CV, Hodgson JM, Randall DD (1988) Subcellular location of NADPH-dependent hydroxypyruvate reductase activity in leaf protoplasts of Pisum sativum L. and its role in photorespiratory metabolism. Plant Physiology 88: 1182

Kossmann J, Sonnewald U, Willmitzer L (1994) Reduction of the chloroplastic fructose1,6-bisphosphatase in transgenic potato plants impairs photosynthesis and plant growth. The Plant Journal 6: 637-650

Li J, Hu J (2015) Using co-expression analysis and stress-based screens to uncover Arabidopsis peroxisomal proteins involved in drought response. PLOS ONE 10: e0137762

Lichtenthaler HK, Wellburn AR (1983) Determination of total carontenoids and chlorophyll a and b of leaf extracts in different solvents. Biochemical Society Transactions 603: 591-592

Livingston AK, Cruz JA, Kohzuma K, Dhingra A, Kramer DM (2010) An Arabidopsis mutant with high cyclic electron flow around photosystem I (hcef) involving the NADPH dehydrogenase complex. Plant Cell 22: 221-233

Peterhänsel C, Krause K, Braun HP, Espie GS, Fernie AR, Hanson DT, Keech O, Maurino VG, Mielewczik M, Sage RF (2013) Engineering photorespiration: current state and future possibilities. Plant Biology 15: 754-758

Pick TR, Bräutigam A, Schulz MA, Obata T, Fernie AR, Weber APM (2013) PLGG1, a plastidic glycolate glycerate transporter, is required for photorespiration and defines a unique class of metabolite transporters. Proceedings of the National Academy of Sciences of the United States of America 110: 3185-3190

Roeske CA, O'Leary MH (1984) Carbon isotope effects on enzyme-catalyzed carboxylation of ribulose bisphosphate. Biochemistry 23: 6275-6284

Sage RF, Sage TL, Kocacinar F (2012) Photorespiration and the evolution of C4 photosynthesis. Annu Rev Plant Biol 63: 19-47

Scheibe R, Geissler A, Fickenscher K (1989) Chloroplast glucose-6-phosphate dehydrogenase: $\mathrm{K}_{\mathrm{m}}$ shift upon light modulation and reduction. Archives of Biochemistry and Biophysics 274: 290-297

Schnarrenberger C, Oeser A (1974) Two isoenzymes of glucosephosphate isomerase from spinach leaves and their intracellular compartmentation. European Journal of Biochemistry 45: 77-82

Sharkey TD (1988) Estimating the rate of photorespiration in leaves. Physiologia Plantarum 73: 147-152 
Sharkey TD (2016) What gas exchange data can tell us about photosynthesis. Plant Cell and Environment 39: 1161-1163

Sharkey TD, Badger MR, Von Caemmerer S, Andrews TJ (2001) Increased heat sensitivity of photosynthesis in tobacco plants with reduced Rubisco activase. Photosynthesis Research 67: 147-156

Sharkey TD, Seemann JR, Berry JA (1986) Regulation of ribulose-1,5-bisphosphate carboxylase activity in response to changing partial pressure of $\mathrm{O}_{2}$ and light in Phaseolus vulgaris. Plant Physiology 81: 788-791

Sharkey TD, Vanderveer PJ (1989) Stromal phosphate concentration is low during feedback limited photosynthesis. Plant Physiology 91: 679-684

Sharkey TD, Vassey TL (1989) Low oxygen inhibition of photosynthesis is caused by inhibition of starch synthesis. Plant Physiology 90: 385-387

Sharkey TD, Weise SE (2012) Autotrophic carbon dioxide fixation. In JJ Eaton-Rye, B Tripathy, TD Sharkey, eds, Photosynthesis: Plastid Biology, Energy Conversion and Carbon Assimilation. Springer Academic Publications, Dordrecht, pp 649-672

Sharkey TD, Weise SE (2016) The glucose 6-phosphate shunt around the Calvin-Benson cycle. Journal of Experimental Botany 67: 4067-4077

Sharkey TD, Weise SE (2017) The glucose 6-phosphate shunt around the Calvin-Benson cycle. Journal of Experimental Botany 68: 4731-4731

Somerville CR (1984) The analysis of photosynthetic carbon dioxide fixation and photorespiration by mutant selection. Oxford Surveys of Plant Molecular \& Cell Biology 1: 103-131

Somerville CR, Ogren WL (1979) Phosphoglycolate phosphatase-deficient mutant of Arabidopsis. Nature 280: 833-836

Stitt M, Zeeman SC (2012) Starch turnover: pathways, regulation and role in growth. Current Opinion in Plant Biology 15: 282-292

Strand DD, Livingston AK, Satoh-Cruz M, Froehlich JE, Maurino VG, Kramer DM (2015) Activation of cyclic electron flow by hydrogen peroxide in vivo. Proceedings of the National Academy of Sciences of the United States of America 112: 5539-5544

Szecowka M, Heise R, Tohge T, Nunes-Nesi A, Vosloh D, Huege J, Feil R, Lunn J, Nikoloski Z, Stitt M, Fernie AR, Arrivault S (2013) Metabolic fluxes in an illuminated Arabidopsis rosette. The Plant Cell Online 25: 694-714

Taylor SH, Long SP (2017) Slow induction of photosynthesis on shade to sun transitions in wheat may cost at least $21 \%$ of productivity. Philosophical Transactions of the Royal Society B: Biological Sciences 372: 20160543

Timm S, Florian A, Jahnke K, Nunes-Nesi A, Fernie AR, Bauwe H (2011) The hydroxypyruvate-reducing system in Arabidopsis: Multiple enzymes for the same end. Plant Physiology 155: 694

Timm S, Mielewczik M, Florian A, Frankenbach S, Dreissen A, Hocken N, Fernie AR, Walter A, Bauwe $\mathbf{H}$ (2012) High-to-low $\mathrm{CO}_{2}$ acclimation reveals plasticity of the photorespiratory pathway and indicates regulatory links to cellular metabolism of Arabidopsis. PLOS ONE 7: e42809

Timm S, Nunes-Nesi A, Pärnik T, Morgenthal K, Wienkoop S, Keerberg 0, Weckwerth W, Kleczkowski LA, Fernie AR, Bauwe H (2008) A cytosolic pathway for the conversion of hydroxypyruvate to glycerate during photorespiration in Arabidopsis. The Plant Cell 20: 2848-2859 
Tolbert NE, Yamazaki RK, Oeser A (1970) Localization and properties of hydroxypyruvate and glyoxylate reductases in spinach leaf particles. Journal of Biological Chemistry 245: 5129-5136

Walker BJ, South PF, Ort DR (2016a) Physiological evidence for plasticity in glycolate/glycerate transport during photorespiration. Photosynthesis Research 129: 93-103

Walker BJ, VanLoocke A, Bernacchi CJ, Ort DR (2016b) The costs of photorespiration to food production now and in the future. Annu Rev Plant Biol 67: 107-129

Xin C-P, Tholen D, Devloo V, Zhu X-G (2015) The benefits of photorespiratory bypasses: how can they work? Plant Physiology 167: 574

Xu H, Zhang J, Zeng J, Jiang L, Liu E, Peng C, He Z, Peng X (2009) Inducible antisense suppression of glycolate oxidase reveals its strong regulation over photosynthesis in rice. Journal of Experimental Botany 60: 1799-1809 


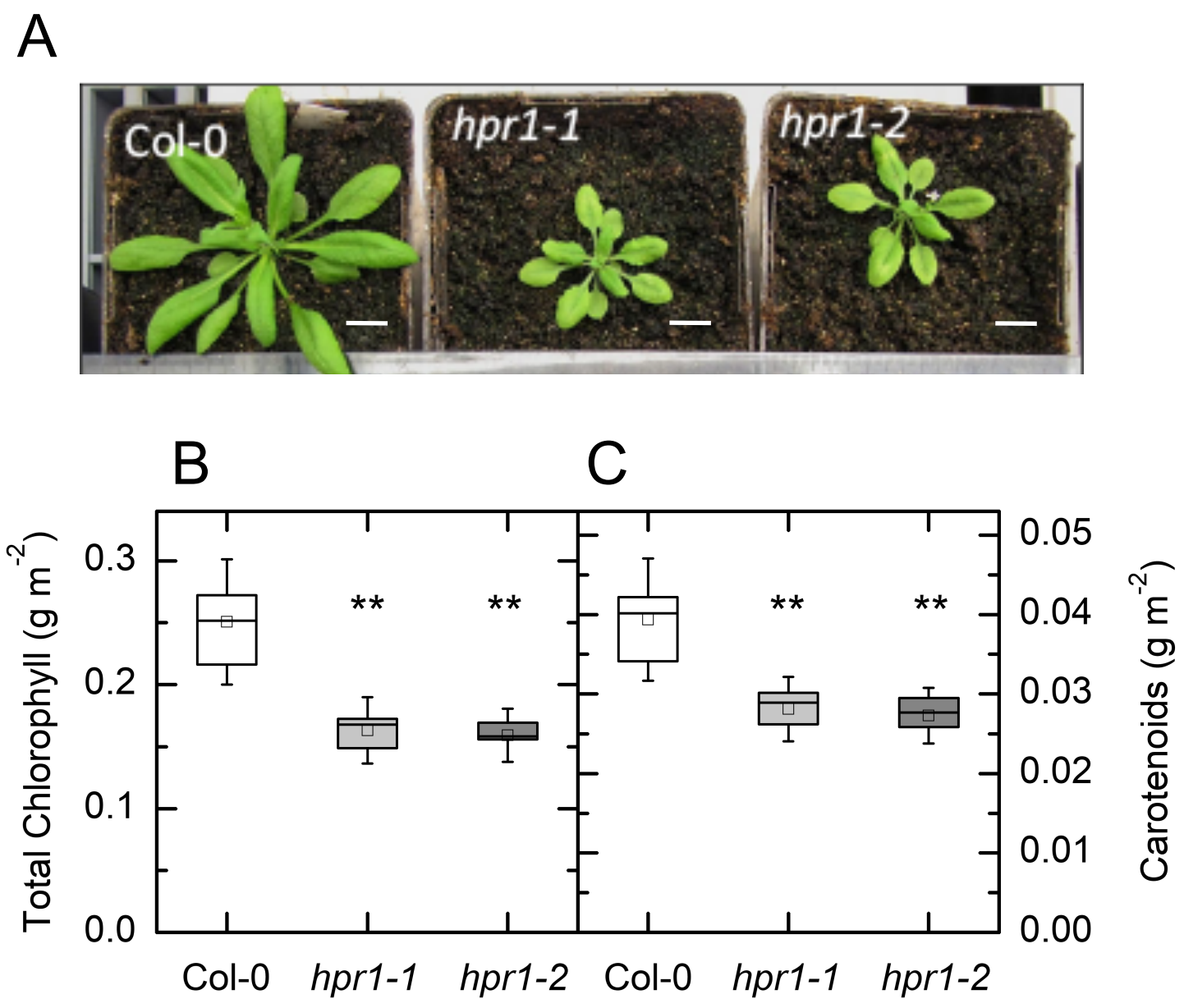

Figure. 1. Rosette appearance of WT, hpr1-1 and hpr1-2 plants and pigments. A) Pictures of two examples of each of three lines of Arabidopsis thaliana growing in soil for four weeks. B) Chlorophyll and C) carotenoid contents. Chlorophyll and carotenoids were measured as described in the materials and methods on leaves of four-week-old plants. White bar in A) is = to 0.5 inch. $\mathrm{n}=6$ 


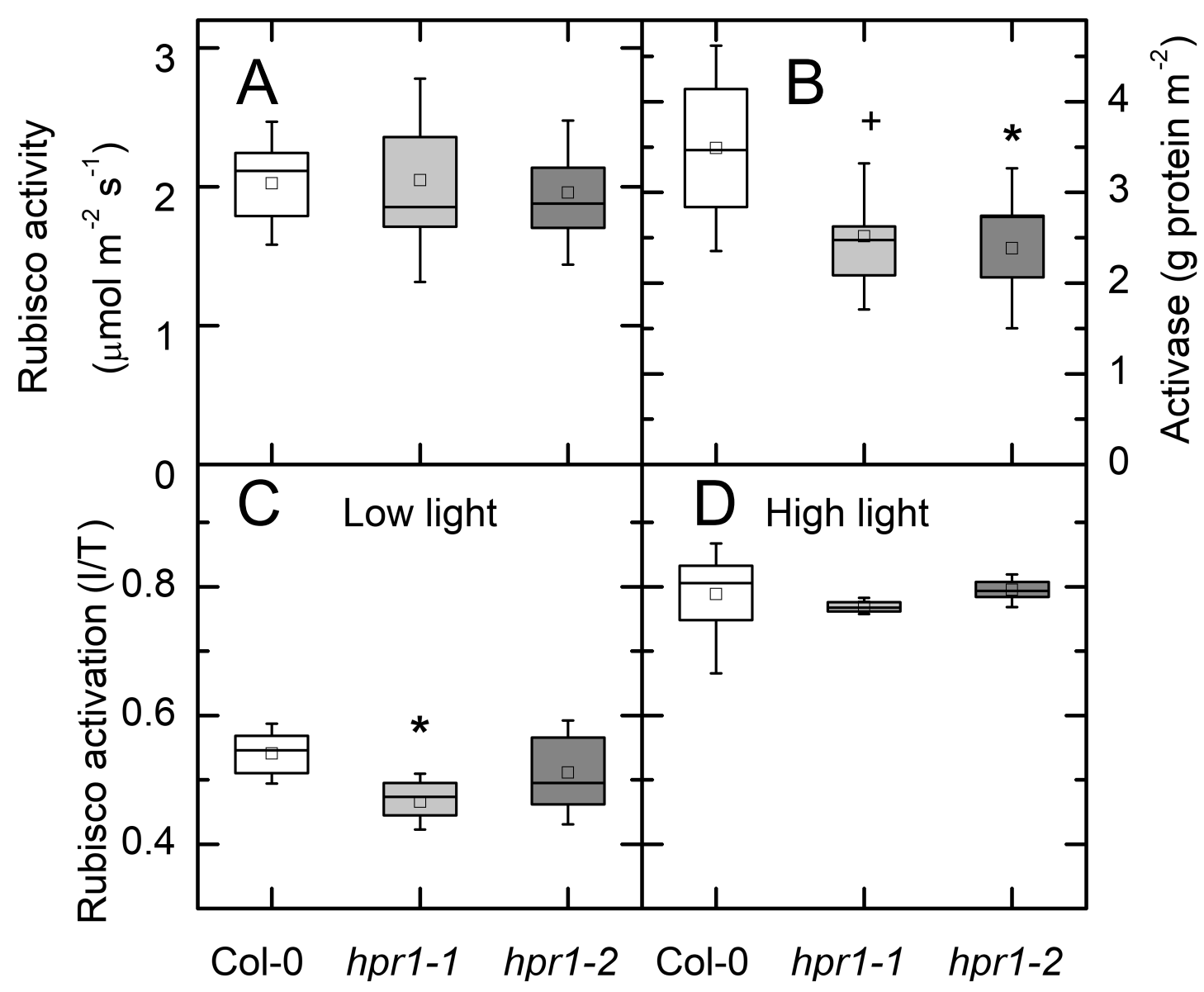

Figure 2. Rubisco activity and activase protein. Total Rubisco activity (A) was the same in Col-0, hprl-1 and hpr1-2. Activase protein (B) was measured using antibodies antibodies raised against rubisco activase and a WES capillary electrophoresis instrument from Protein Simple. Rubisco activation state is presented as the ratio between initial (measured as quickly as possible after extraction) and total (after incubation with $\mathrm{HCO}_{3}$ and $\mathrm{Mg}$ ) at 125 (C) or 1000 (D) $\mu \mathrm{mol}$ photons $\mathrm{m}^{-2} \mathrm{~s}^{-1}$. For a, c, and $\mathrm{d} \mathrm{n}=4-7$. For $\mathrm{b}$, data were not different between the low and high light treatment and so was combined, $\mathrm{n}=7-8$. 


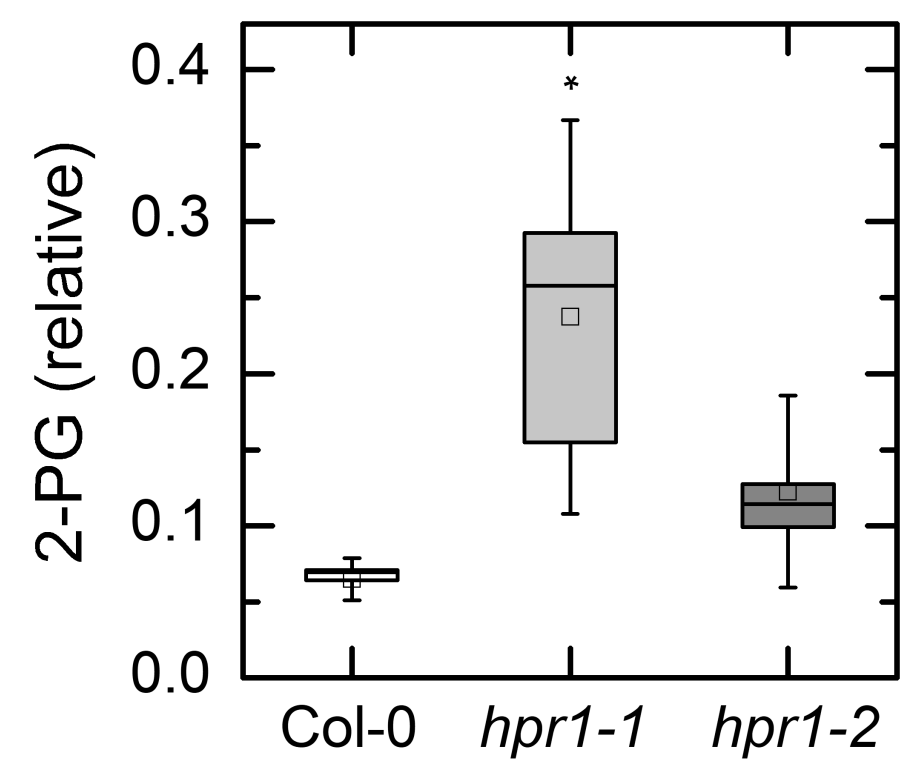

Figure 3. 2-phosphoglycolate (2-PG) amounts in leaves of Col-0 and two HPR mutants. 2PG was measured by HPLC-MS/MS leaves were harvested after $6 \mathrm{hr}$ in 125 or $1000 \mu \mathrm{mol}$ photons $\mathrm{m}^{-2} \mathrm{~s}^{-1}$. Because the data for both light intensities was indistinguishable they were combined to increase statistical power. Data are expressed as peak area of 2-PG divided by peak area of the internal standard relative to weight of plant material extracted. The results in high and low light were not different and so all of the data was combined. $n=7-8$ 


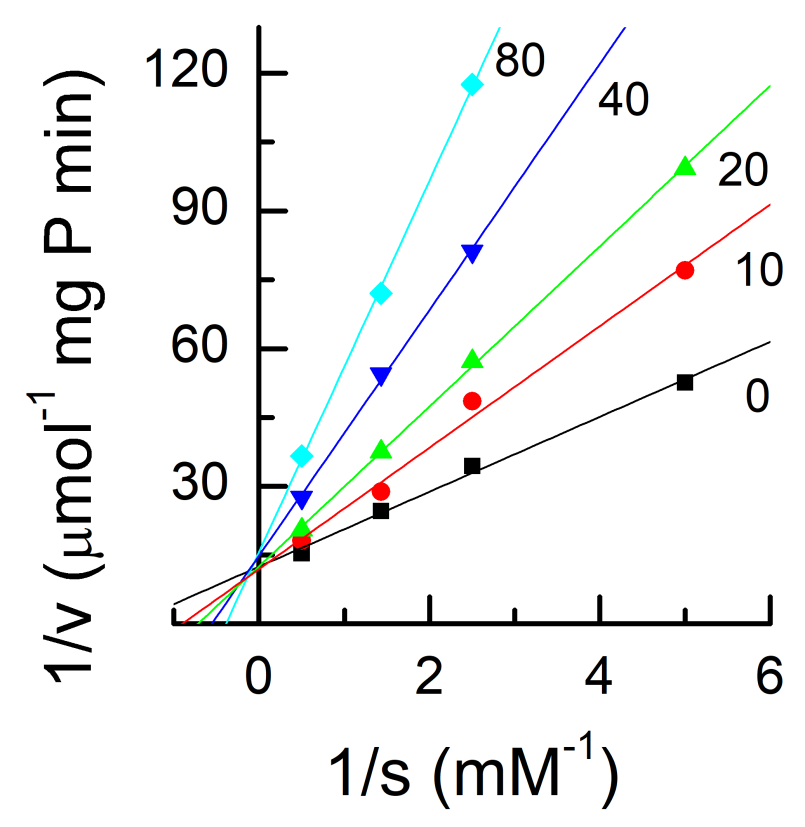

Figure 4. Lineweaver-Burke plot of triose phosphate isomerase activity. Triose phosphate isomerase in crude extracts of Arabidopsis leaves was assayed in the presence of a range of GAP and 2-PG concentrations. The numbers on each line is the concentration of 2-PG in $\mu \mathrm{M}$. The crossover of the lines at the $\mathrm{y}$ axis indicates that 2-PG is a competitive inhibitor. 


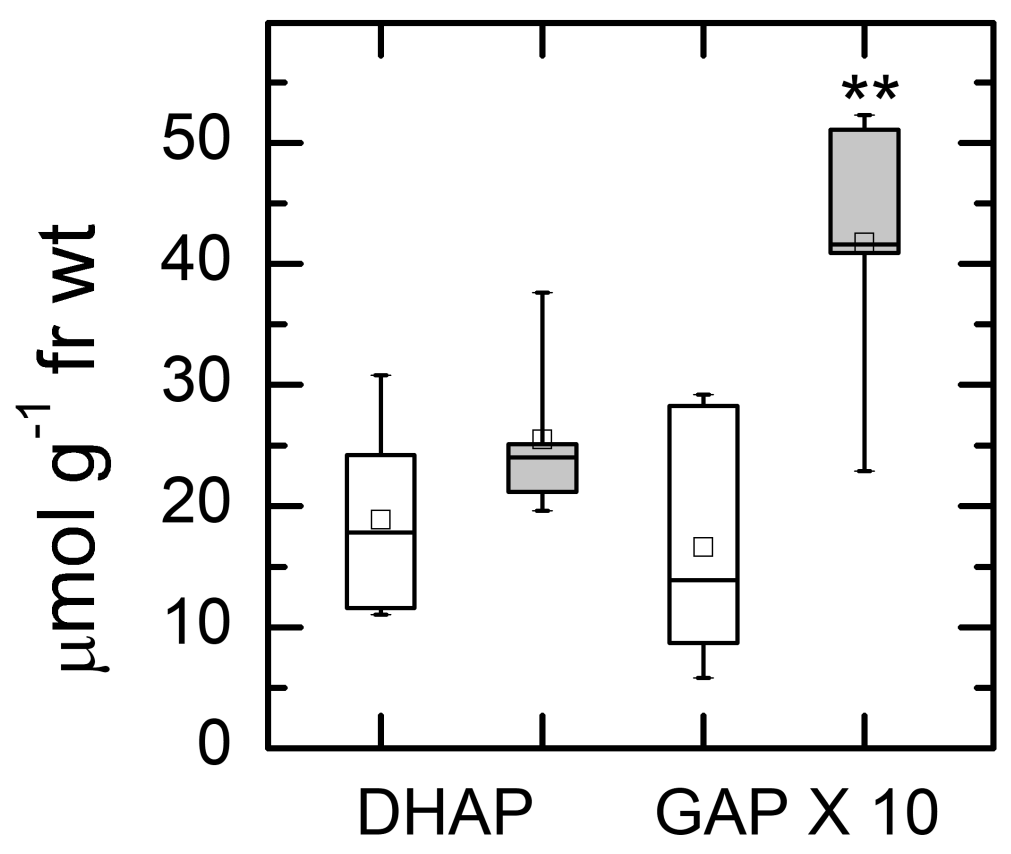

Figure 5. Amounts of DHAP and GAP. Leaves were treated with $1000 \mu \mathrm{mol}$ photons $\mathrm{m}^{-2} \mathrm{~s}^{-1}$ for six hours, then clamped with liquid-nitrogen-cooled copper blocks to stop metabolism in the light. Leaf samples were extracted with perchloric acid, neutralized, and then measured using sequential additions of GAP dehydrogenase and TPI while following NADH production photometrically. Unfilled boxes $-125 \mu \mathrm{mol}$ photons $\mathrm{m}^{-2} \mathrm{~s}^{-1}$ low light, grey boxes $-1000 \mu \mathrm{mol}$ photons $\mathrm{m}^{-2} \mathrm{~s}^{-1}$ high light. $\mathrm{n}=5$ 


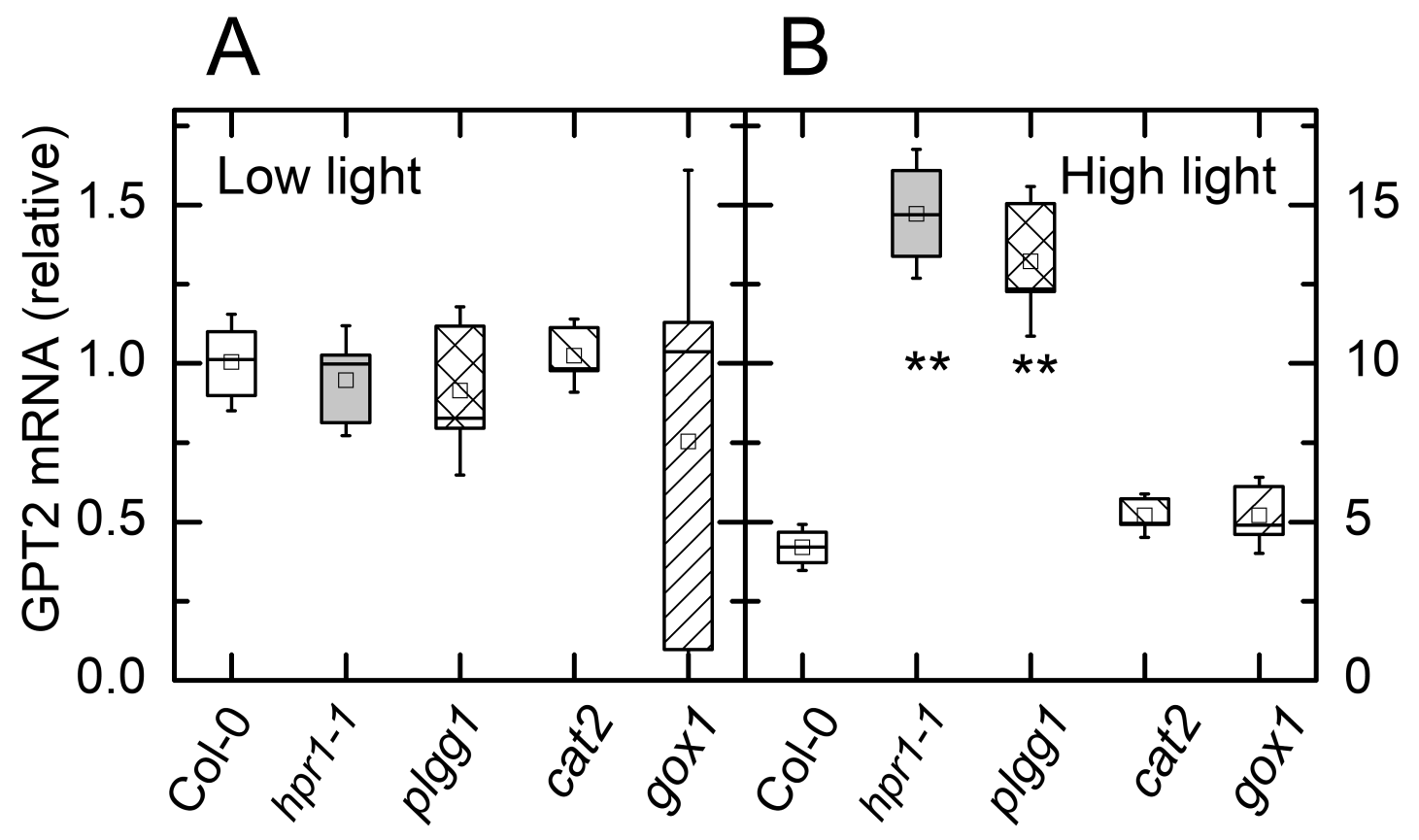

Figure 6. Quantitative RT-PCR analysis of GPT2 transcripts in low and high light.

Transcripts were measured in four photorespiratory mutant lines and WT (Col-0) in plants taken from A) low light intensity $\left(125 \mu \mathrm{mol} \mathrm{m}^{-2} \mathrm{~s}^{-1}\right)$ and after six hr B) high light $\left(500 \mu \mathrm{mol} \mathrm{m} \mathrm{m}^{-2} \mathrm{~s}^{-1}\right)$. Note the scale is 10 -fold higher for the high light data, thus GPT2 transcript was about four-fold higher after the high light treatment. $n=3$ 


\section{Col-0}

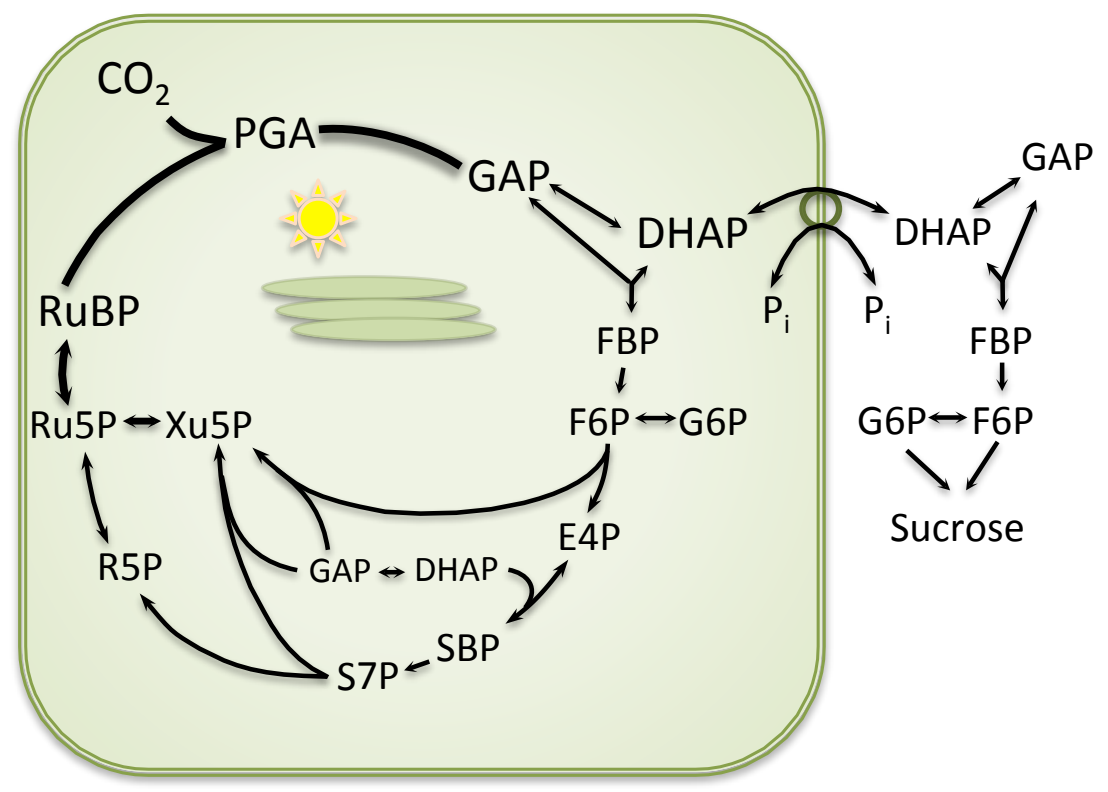

hpr1-1

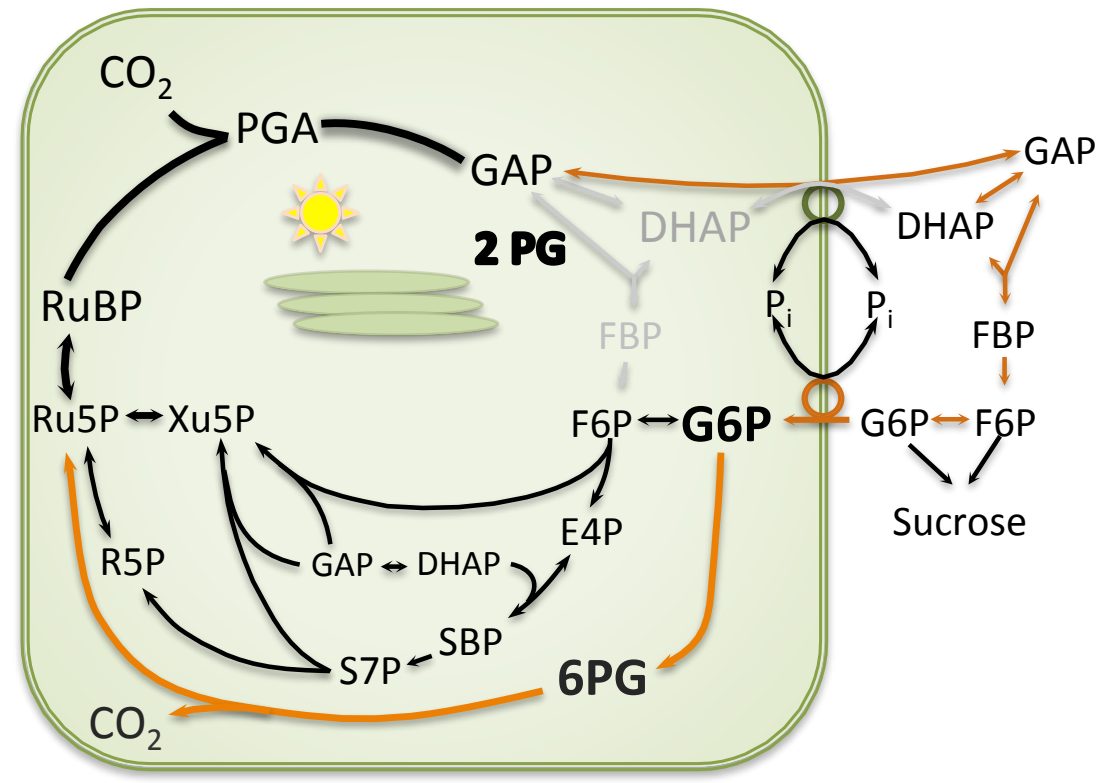

Figure 7. Hypothesized carbon flow in Col-0 and hpr1-1. The canonical path of carbon in the Calvin-Benson cycle plus sucrose synthesis is shown for Col-0. In hpr1-1 plants we hypothesize that 2-PG inhibits TIM forcing export of GAP. Once acted on by cytosolic TIM some DHAP will be reimported but the gradient in phosphate is not favorable for this flux. The triose phosphates in the cytosol will be converted eventually to Glc-6-P. Some unknown 
signal results in the expression of GPT2 allowing reimport of carbon as Glc-6-P. This allows some Calvin-Benson cycle activity but also stimulates the Glc-6-P shunt (shown in orange). The stimulated Glc-6-P shunt is balanced in terms of carbon and NADPH but reduces ATP availability. Another unknown signal results in cyclic electron flow. PGA = phosphoglyceric acid, GAP = glyceraldehyde 3-phosphate, DHAP, dihydroxyacetone phosphate, FBP = fructose 1,6-bisphosphate, F6P = fructose 6-phosphate, E4P = erythrose 4-phosphate, S7P = sedoheptulose 7-phosphate, $\mathrm{R} 5 \mathrm{P}=$ ribose 5 -phosphate, $\mathrm{XuBP}=$ xylulose 5 -phosphate, Ru5P $=$ ribulose 5 -phosphate, $\mathrm{RuBP}=$ ribulose 1,5 -bisphosphate, $\mathrm{SBP}=$ sedoheptulose 1,7bisphosphate, $6 \mathrm{PG}=6$-phosphoglucanate. 